\title{
Inspanning all the oxen - new Health Foundation
}

The Western Cape is pioneering an independent fund-raising foundation that will help its provincial health department to reduce the regional burden of disease through wellness programmes, infrastructure upgrades and mutually beneficial public-private partnerships.

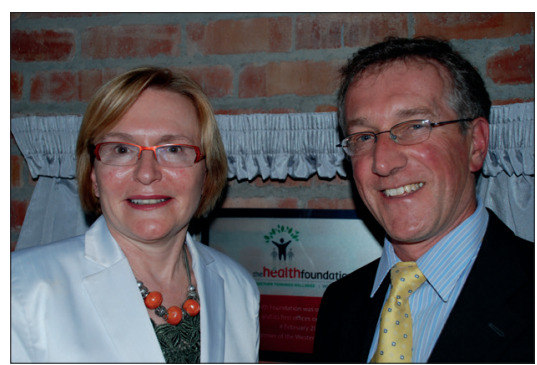

Western Cape Premier Helen Zille and Health Foundation CEO Dr Josh Fisher.

Initially aimed at reducing, among other things, what Health MEC Theuns Botha estimates as a R1 billion backlog in infrastructure maintenance, the multifaceted strategy (as embodied by the new Health Foundation) is a 'holistic, all hands on deck' approach. Speaking at the opening of the Foundation's offices in Stellenbosch on 4 February this year, its CEO, Dr Joshua Fisher, said accelerating and spreading wellness programmes through employer programmes at the workplace and at schools, replicating the hugely successful Red Cross Children's War Memorial Hospital fund-raising model at other facilities, and up-skilling (or merely rendering functional) health facility boards would be pivotal. The Foundation was also positioning itself to broker 'significant deals with private companies' to enable the generation of rental income and fees.

Creating the space for innovation ... Elaborating, he described the emergence of previously unheard-of retail operations in 'appropriate' public health spaces, the selling of 'appropriate' advertising on and in public health facilities, and the exploration of 'any other' sustainable commercial partnerships that generated revenue. Some projects were already in the pilot phase, while major corporations were being invited to donate start-up capital via a once-off R500 000 investment in the Foundation. In return, they would receive prime marketing exposure for 3 years, feature prominently on the letterheads of Foundation-printed material and on its website, plus secure the right-of-first-refusal on any future donor or commercial projects. Only one Foundation partner would be allowed from each commercial sector (e.g. pharmaceuticals or banking), thus guaranteeing exclusivity. Fisher revealed that Philips South Africa was the first to commit R500 000 in startup funds, prompting a flurry of 'highly promising' enquiries from other major corporations.

\section{Accelerating and spreading wellness programmes through employer programmes at the workplace and at schools, replicating the hugely successful \\ Red Cross Children's War Memorial fund-raising model at other facilities. Meanwhile, up-skilling (or merely rendering functional) health facility boards, would be key.}

Western Cape Premier Helen Zille said that adopting a 'whole-of-society' model was central to her government's strategy in reducing the burden of disease and encouraging individuals, families and communities to take responsibility for the quality of their own lives. Her province's population had grown by $30 \%$ between the last 2 censuses, yet there remained an unrealistic expectation that if people are to rise out of poverty, they be taken out of it by government'. While agreeing that government's job was 'to provide the basics', she said doing this merely created a context in which people could use their freedom to choose, instead of what she cited as 'a debilitating dependence on victimhood'. She said that up to $80 \%$ of her health department's budget was spent on (lifestyle) diseases that people could, if they took responsibility, 'choose not to get'. 'Healthcare has to happen in the context of partnership. People must take responsibility to stay well. Not drink and drive and not have inter-generational sex and multiple partners', she added.

\section{Legal minefields cleared for} corporate vehicles

Botha, whose brainchild the Foundation is, told the launch, attended by a cross-section of top provincial health officials, academics and health-related corporate executives, that in order to navigate through the minefield of Treasury and other regulations, he had appointed a top auditing firm to probe what kind of structure could legitimately assist his department to achieve its goals. The auditing firm also probed commercial naming rights in South Africa, the United Kingdom and the United States to ease the way for public/ private partnerships. He described the new venture as 'a wonderful opportunity to grow medium and small businesses in the health sector and ensure they are feasible while harnessing significant cross-sector expertise? His department dealt with 23 million patient 
visits a year with more than 20 million 'interactions' through outreach and homebased care projects, using more than 600 facilities run by over 30000 staff. He said that in spite of increasing staff by 4000 people over the past 3 years, 'we're still not achieving wellness'. There was 'simply no option' to use any more existing taxpayermoney or to divert public funds to Health (the biggest provincial budget allocation, even ahead of education). He cited the recent $30 \%$ increase in patient loads for mental health, a function of rampant drug and alcohol abuse which forced his government to 'keep on adding huge emergency centres' to existing hospitals.

Earlier, Zille told the audience that there were 27 drug rehabilitation centres in the Western Cape (4 having been built since her party took office, with more in the pipeline). One pivotal treatment intervention involved undergraduate and post-graduate publicprivate partnerships with the universities of Cape Town and Stellenbosch to enable the training of 'addiction specialists', for whom there was an obvious need. She described the drug education component of the Western Cape schools 'life orientation' education curriculum as 'among the best in the world'. Highlighting the impact that dysfunctional families had on health, she said that while $80 \%$ of white children came from two-parent families, only $30 \%$ of black children did, often with functionally illiterate parents and no access to good schools. Her government had built a network of basket-ball courts and sports fields across the region, hoping to divert children's attention away from unhealthy activities. However, mothers came to her saying these merely turned into new outlets for drug dealers. 'They would rather have their kids in the house', she said. Punting his province's public health sector attributes (in particular the academic input), Botha said the tertiary hospital-linked university health faculties had invented the world-famous CAT scan and pioneered heart surgery while boasting 'world-class' disease management. 'We're not perfect by a long shot, but we're doing our best trying to improve, be accountable and listen to what our critics say, he added.
The Foundation will be chaired by renowned neurosurgeon, environmentalist and Elgin winemaker Dr Paul Cluver who broke new ground 6 years ago when he established the now internationally known Thandi Wines, South Africa's first agricultural black economic empowerment (BEE) project. The company is co-owned by 250 farmworker families who hold 55\% shares in the company, with land rights over 3 farms which they either partially or wholly own. Cluver said the Health Foundation would provide better access to quality health care 'in the face of infinite demand'. The newly appointed board had a 'diverse and accomplished set of skills and expertise' and shared a passion for making a difference to society in general and healthcare in particular. He emphasised that the Foundation was non-profit, independent and non-politically aligned.

\section{Chris Bateman}

chrisb@hmpg.co.za

$S$ Afr Med J 2013;103(4):217-218.

DOI: $10.7196 / 6863$ 